REVIEW ARTICLE

DOI: $10.1038 / s 41467-018-06779-w$

\title{
OPEN
}

\section{Ecology and evolution of facilitation among symbionts}

Flore Zélé (i) ${ }^{1}$, Sara Magalhães (1) ${ }^{1}$, Sonia Kéfi ${ }^{2}{ }^{2}$ \& Alison B. Duncan (1) ${ }^{2}$

Facilitation occurs when one species positively impacts the fitness of another, and has predominantly been studied in free-living species like plants. Facilitation can also occur among symbiont (mutualistic or parasitic) species or strains, but equivalent studies are scarce. To advance an integrated view of the effect of facilitation on symbiont ecology and evolution, we review empirical evidence and their underlying mechanisms, explore the factors favouring its emergence, and discuss its consequences for virulence and transmission. We argue that the facilitation concept can improve understanding of the evolutionary forces shaping symbiont communities and their effects on hosts.

\footnotetext{
${ }_{1}^{1}$ CE3c: Centre for Ecology, Evolution, and Environmental Changes, Faculty of Sciences, University of Lisbon, Edifício C2, piso-3, 1749-016 Lisboa, Portugal. ${ }^{2}$ ISEM, Université de Montpellier, CNRS, EPHE, IRD, Montpellier Cedex 05, France. Correspondence and requests for materials should be addressed to A.B.D. (email: alison.duncan@umontpellier.fr)
} 
$\mathrm{t}$ is now widely accepted that interacting species can positively impact one another ${ }^{1-5}$. Facilitation (Box 1) is one of the broadest terms referring to these positive interactions (Fig. 1). Its history is anchored in that of plant-plant interactions, although its realm has recently been extended to include other $\operatorname{taxa}^{1}$. Studies to date generally document its occurrence, and the ecological consequences of facilitation for individuals, species and ecosystems. The evolutionary causes and consequences of these interactions, though tackled using modelling approaches ${ }^{6}$ and phylogenetic analyses ${ }^{7}$, are still poorly assessed via contemporary evolution studies ${ }^{2}$. Despite the ubiquity of organisms that live within or upon others (endo or ecto-symbionts, hereafter 'symbionts' for brevity; Box 1), facilitation between symbionts has been largely overlooked. Indeed, individual hosts are often colonised by multiple symbionts, which can have positive, negative or neutral effects on one another (Fig. 1), independently of their effect on the host (e.g. either parasitic, commensal or mutualistic). Symbiont-symbiont competition has been shown both empirically and theoretically to have diverse effects on symbiont ecology and evolution ${ }^{8}$, but corresponding studies about facilitation in multiple infections (Box 1) are lacking. The host-symbiont literature contains many examples of symbiont-symbiont interactions compatible with facilitation (see Supplementary Table 1), though the interactions are rarely identified as such and are not unified into a common body of work. Moreover, a number of these studies investigate the evolutionary outcomes of facilitation $^{9,10}$, which may be relevant for the interpretation of ecological patterns observed in both symbiotic and free-living systems.

Several reviews state that facilitative interactions have been relatively neglected in ecological theory, despite abundant empirical evidence for their occurrence in natural populations and indication of their importance for community functioning and stability ${ }^{1,2,5}$. Here, we argue that facilitation has been particularly overlooked in the symbiont literature ${ }^{4}$. The aim of this review is to highlight that integrating approaches used to study facilitation in free-living organisms with studies of symbionts will be highly informative and beneficial for both fields of research. On the one hand, placing symbiont-symbiont interactions in the context of facilitation should increase our understanding about infection outcomes. On the other hand, because it is easier to study evolution in symbionts than in most free-living organisms (given their shorter generation time), studies of symbiont-symbiont facilitation may guide predictions about how positive interactions between species could shape evolution in free-living communities.

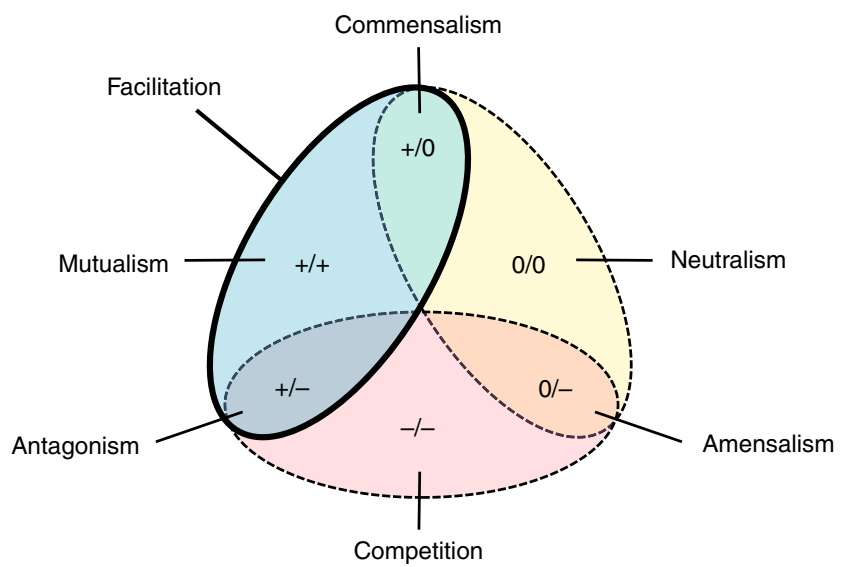

Fig. 1 Diagram showing the different types of ecological interactions. 0: no effect; -: negative effect; +: positive effect. Facilitation includes mutualistic, commensal and antagonistic interactions
First, we outline the different mechanisms of symbiont-symbiont facilitation. Next, we investigate the ecological and evolutionary conditions favouring the occurrence and maintenance of facilitation between symbiotic organisms. Finally, we discuss the ecological and evolutionary consequences of facilitation, and suggest future research avenues. Throughout, we highlight parallels with free-living organisms.

\section{Mechanisms of facilitation}

Symbionts can facilitate each other either directly (independently of the host) or indirectly (via host manipulation) and facilitation can occur both within- and between-hosts (Fig. 2). Overall, the mechanisms of facilitation between symbionts are similar to those found between free-living organisms (summarised in Fig. 3, along with some chosen examples; see also ref. ${ }^{11}$, and Supplementary Table 1 for more examples of facilitation between symbionts).

Direct facilitation. Some symbionts directly facilitate the growth or reproduction of others, by producing substances aiding them to exploit the host (i.e. 'supplied-product' facilitation) ${ }^{12,13}$. Direct facilitation can occur when a symbiont facilitates another by affecting its gene expression (i.e. transactivation) ${ }^{14}$ or by providing essential gene products such as in the case of transcapsidation $^{15}$ or helper component-transcomplementation ${ }^{15,16}$. Direct facilitation can also arise when exogenous genetic material from one symbiont becomes integrated in another (i.e. nested symbionts $)^{17}$.

Indirect facilitation. Within-host indirect facilitation can be mediated by the modification of host resources used by symbionts $^{18}$, or by improving host fitness in ways that benefit other symbionts. For instance, by increasing host longevity, a symbiont can reduce the survival cost of infection by another parasite ${ }^{19}$, which, in turn enhances the probability that the latter completes its development within the host.

Indirect facilitation also occurs via the host immune system. This can be brought about by immune-evasion strategies such as immunosuppression, which might be advantageous for other symbionts within the host ${ }^{14}$, or via immunological trade-offs, whereby a host is unable to simultaneously mount immune responses against different symbionts ${ }^{20-22}$. Furthermore, symbionts can facilitate host entry or exit of another ${ }^{4}$ via epidermal injuries $^{23}$ or through the symptoms of infection ${ }^{24}$.

Finally, behavioural or reproductive manipulation of the host by a symbiont can facilitate the transmission (Box 1) of other symbionts (e.g. 'hitch-hiking') ${ }^{25}$. This might occur between horizontally transmitted symbionts with complex life cycles that share both intermediate and definitive hosts ${ }^{25}$, as well as between symbionts with different transmission routes $^{26}$ (Box 1 ). Vertically transmitted reproductive manipulators that increase the proportion of infected female offspring in the population ${ }^{27}$ can also facilitate the transmission of other vertically transmitted symbionts (i.e. via synergy or hitchhiking) ${ }^{27,28}$.

\section{Multiple mechanisms and multiple effects}

Facilitation is often not easily attributed to a single mechanism. For example, HIV-1 triggers lymphocyte activation, and activated lymphocytes are the preferred resource of the human cytomegalovirus ${ }^{29}$. Hence, facilitation is immune-mediated from the facilitator perspective, but resource-mediated for the facilitated. Moreover, several facilitating mechanisms can operate simultaneously. For instance, the direct facilitation of polydnavirus transmission by parasitoid wasps described in Fig. 3 is accompanied by an indirect facilitation by the virus for wasps, via silencing of the host immune system ${ }^{17}$. Importantly, many (if not 


\section{Box 1. Glossary}

Co-transmission: two or more symbionts are transmitted together, sometimes packaged together in the same protein case.

Facilitation: any interaction where the action of one symbiont has a beneficial effect on another. This includes mutualistic interactions where both the facilitated and facilitator benefit $(+/+)$, those which are commensal $(+/ 0)$ when the effects of the facilitated on the facilitator are neutral as well as those which are antagonistic $(+/-)$ when the facilitated negatively impact the facilitator (Fig. 1). Note that this concept partially overlaps with that of mutualism, ecological engineering and niche construction.

Multiple infection: the presence of more than one symbiont (strain or species) circulating in an individual or population.

Symbiont: As defined by Anton de Bary (1879): 'the living together of unlike organisms', we use this term to refer to any organism residing within or on hosts, encompassing all species along the mutualist-parasite continuum (i.e. they can be mutualists, commensalists or parasites of the host).

Syntrophy: nutritional relationship between two organisms that combine their metabolic abilities to use a substrate that they could not use otherwise. A special case of syntrophy is cross-feeding, in which two organisms feed on the waste products of each other.

Transmission: the passage of a symbiont from one host to another.

Transmission mode: the relationship between hosts among which symbionts are transmitted. Vertical transmission occurs from parent to offspring; horizontal transmission from infected to uninfected hosts, via non-hereditary mechanisms, often the environment; and mixed transmission is a combination of vertical and horizontal transmission.

Transmission route: the means that symbionts use to pass from one host to another (e.g. body fluids, a vector, spores in the environment). 'Direct contact transmission' is through host-to-host contact (e.g. coughing), whereas indirect transmission occurs via a vector (i.e. the environment or another host).

Virulence: symbiont-induced reduction in host fitness.

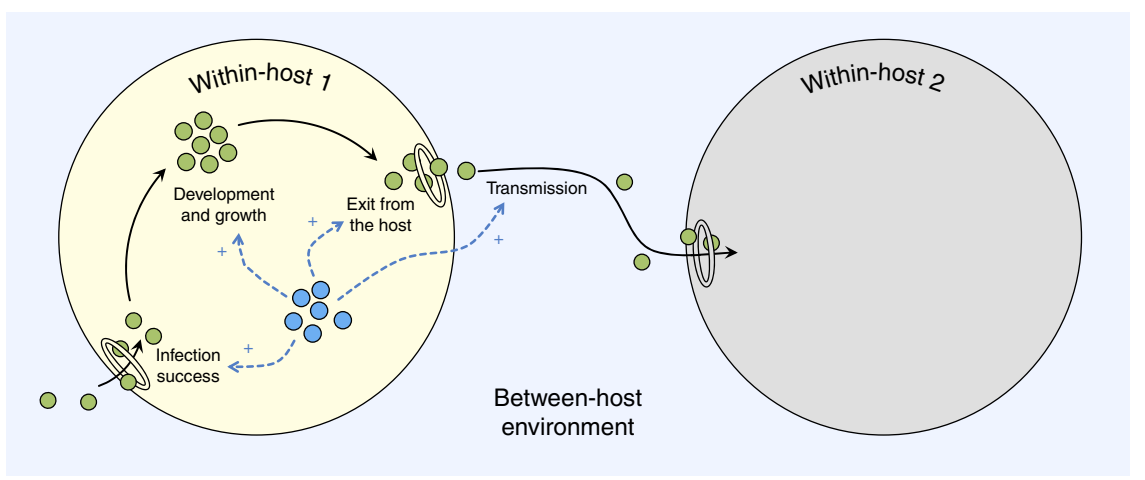

Fig. 2 Facilitation between symbionts can occur within or between hosts. Small blue circles: facilitating symbionts; small green circles: facilitated symbionts; big yellow circle: co-infected host; big grey circle: uninfected host; rings: entry/exit point of the host; blue dashed arrows: facilitation; black solid arrows: transition between life cycle stages of the facilitated symbiont. Traits facilitated are categorised as 'development' (i.e. symbiont growth or differentiation) in the within-host environment, 'infection success' (i.e. host entry or establishment), 'exit from the host' at the interface between the within- and betweenhost environment, and 'transmission' in the between-host environment. Note that the diagram does not consider the symmetry of the interaction (i.e. the effect of the facilitated symbiont on the facilitator is not represented)

all) multiple infections entail some degree of competition between symbionts. This means that interactions between the same two organisms can be both facilitative and competitive, changing at different life-stages or in different environments ${ }^{11}$. Moreover, facilitation and competition can occur over the same resource/ common good (Fig. 3), or facilitation might occur for one trait and competition for another ${ }^{30}$. For example, simultaneous infection of rabbits by two helminth species increases the density but decreases the fecundity of one symbiont, while having the opposite effect on the other ${ }^{31}$. Whether this can be considered as facilitation is debatable, and would ultimately require measuring the transmission of each parasite to new hosts, to ascertain whether the net direction of the interaction is negative or positive.

Similarly, it is not always clear whether competition or facilitation is the dominant interaction between a facilitator and a facilitated individual in plant species pairs ${ }^{32}$ (but see ref. ${ }^{33}$ ). Consequently, the net effect of a facilitator on a facilitated results from unequal negative and positive effects, and some consider that the term 'facilitation' should be reserved for cases where positive effects dominate ${ }^{11}$. The interplay between competition and facilitation forms the basis of a classical prediction in the ecological literature, the stress-gradient hypothesis ${ }^{34}$ : it states that positive interactions should be more frequent under more stressful environmental conditions, whereas negative interactions are expected to be more frequent under benign conditions ${ }^{34}$. A recent meta-analysis confirmed that competitive interactions declined with increasing stress between 727 pairs of plant species $^{35}$. Whether this holds for pairs of symbiont species remains to be tested.

Another issue arises from potential correlations between symbiont life-history traits at the within/between-host level ${ }^{36}$. Indeed, a facilitator causing higher within-host symbiont growth might be assumed to also increase transmission (as these traits are often positively correlated and linked to fitness ${ }^{37}$ ). However, this does not always hold true. For instance, in Culex pipiens mosquitoes, Wolbachia increases Plasmodium relictum infection success and within-host growth, but not the number of transmissible stages ${ }^{38}$. Moreover, by increasing symbiont load, the presence of a facilitator can induce increased virulence (Box 1), which, in turn, might reduce transmission 


\begin{tabular}{|c|c|c|c|c|}
\hline \multirow{2}{*}{\multicolumn{2}{|c|}{$\begin{array}{l}\text { Types of facilitation } \\
\text { Direct (via gene products of the facilitator) }\end{array}$}} & Trait(s) facilitated & Examples for symbiont interactions & Examples for free-living organisms \\
\hline & & & & \\
\hline $\begin{array}{l}\text { 'Supplied-product' } \\
\text { The substances produced ( }+: \\
\text { waste or public goods) by one } \\
\text { symbiont (O) directly benefit } \\
\text { another (O). }\end{array}$ & $\int_{0.000}^{000}$ & Development & $\begin{array}{l}\text { Extracelluar digestion of a dietary } \\
\text { fructan }(+) \text { by the human gut bacteria } \\
\text { Bacteroides ovatus }(0) \text { benefits } \\
\text { B. vulgatus (O) via cross-feeding }{ }^{13} \text {. } \\
\text { Sulphur-oxidiser }(0) \text { and } \\
\text { sulphate-reducer }(0) \text { bacteria in the marine } \\
\text { invertebrate Olavius algarvensis engage in } \\
\text { mutually beneficial syntrophy }{ }^{12} \text {. }\end{array}$ & $\begin{array}{l}\text { Free-living decomposer bacteria } \\
\text { naturally co-occurring in diverse } \\
\text { communities feed on the waste } \\
\text { products of other bacteria }{ }^{48} \text {. }\end{array}$ \\
\hline \multicolumn{5}{|l|}{ Genome expression } \\
\hline $\begin{array}{l}\text { Transactivation: } \\
\text { The gene products of one } \\
\text { symbiont (o) induce gene } \\
\text { transcription }(\%) \text { in another }(0) .\end{array}$ & & Development & $\begin{array}{l}\text { The Herpes simplex virus (HSV) (O) } \\
\text { enhances HIV-1 }(0) \text { replication via proteins } \\
\text { that interact with the long terminal repeat } \\
\text { region }(\not 1)^{14} \text {. }\end{array}$ & $\begin{array}{l}\text { Expression of plant immune genes } \\
\text { can be mediated by volatile } \\
\text { compounds produced by } \\
\text { conspecific or heterospecific } \\
\text { neighbouring plants }{ }^{87} \text {. }\end{array}$ \\
\hline $\begin{array}{l}\text { Helper component- } \\
\text { transcomplementation: } \\
\text { The gene products }(\uparrow) \text { of one } \\
\text { symbiont }(0) \text { aid another }(0) \\
\text { to exploit host cells }(O) \text { and } \\
\text { transmit. }\end{array}$ & & $\begin{array}{l}\text { Development } \\
\text { Transmission }\end{array}$ & $\begin{array}{l}\text { A helper-component protease }(+) \text { coded by } \\
\text { one virus (O; e.g. Potyvirus) enables virus } \\
\text { particles of another ( } O \text {; e.g. Cauliflower } \\
\text { mosaic virus) to bind to host cells (O) and } \\
\text { transmit }^{15,16} \text {. }\end{array}$ & $\begin{array}{l}\text { Toxins from the golden poison dart } \\
\text { frog Phyllobates terribilis, are used } \\
\text { by native South Americans from } \\
\text { the Pacific slopes of the Andes in } \\
\text { Colombia to tip their blowgun } \\
\text { darts }^{88} \text {. }\end{array}$ \\
\hline $\begin{array}{l}\text { Transcapsidation: } \\
\text { The gene products of one } \\
\text { symbiont (O) protect } \\
\text { another (O) outside the host. }\end{array}$ & & $\begin{array}{l}\text { Exit from the host } \\
\text { Transmission } \\
\text { Infection success }\end{array}$ & $\begin{array}{l}\text { Umbraviruses }(0) \text { use the capsid protein of } \\
\text { luteoviruses }(0) \text { to form vector- } \\
\text { transmissible hybrid virus particles }^{15}\end{array}$ & $\begin{array}{l}\text { Nudibranchs acquire and use } \\
\text { nematocysts (defensive weapons) } \\
\text { from predation of cnidarians }{ }^{89}\end{array}$ \\
\hline $\begin{array}{l}\text { Nested symbionts: } \\
\text { A symbiont (O) integrates the } \\
\text { genetic material ("/) of } \\
\text { another (O). }\end{array}$ & & $\begin{array}{l}\text { Infection success } \\
\text { Development } \\
\text { Transmission }\end{array}$ & $\begin{array}{l}\text { Polydnaviruses (O; Braco- and Ichno- } \\
\text { viruses) are integrated in the genome of } \\
\text { parasitoid wasps ( } \mathrm{O} \text {; Braconidae and } \\
\text { Ichneumonidae), and benefit from vertical } \\
\text { transmission in wasp eggs }{ }^{17} \text {. }\end{array}$ & $\begin{array}{l}\text { The sea slug Elysia chlorotica } \\
\text { harvests plastids from its } \\
\text { heterokont algal prey, Vaucheria } \\
\text { litorea, for photosynthesis }\end{array}$ \\
\hline \multicolumn{5}{|c|}{ Indirect (mediated by modification of the host by the facilitator) } \\
\hline $\begin{array}{l}\text { Resource-mediated } \\
\text { One symbiont }(0) \text { improves the } \\
\text { resource environment (O: } \\
\text { quantity or quality; host fitness) } \\
\text { for another symbiont (O). }\end{array}$ & $\stackrel{\circ}{\circ}$ & $\begin{array}{l}\text { Infection success } \\
\text { Development }\end{array}$ & $\begin{array}{l}\text { Plasmodium chabaudi }(O) \text { increases host } \\
\text { reticulocyte (O; young red blood cells) } \\
\text { production, which is the preferred niche of } \\
\text { P. yoelii }(0)^{18} \text {. }\end{array}$ & $\begin{array}{l}\text { Nurse plants improve nutrient and } \\
\text { water availability for beneficiary } \\
\text { plants }\end{array}$ \\
\hline \multicolumn{5}{|l|}{ Immune-mediated } \\
\hline $\begin{array}{l}\text { Immunosuppression: } \\
\text { One symbiont (O) } \\
\text { downregulates host immune } \\
\text { responses }(\diamond) \text {, and this benefits } \\
\text { a second symbiont }(0) \text {. }\end{array}$ & & $\begin{array}{l}\text { Infection success } \\
\text { Development }\end{array}$ & $\begin{array}{l}\text { HIV- } 1(0) \text { infection, facilitates additional } \\
\text { infections by HSV }(O)^{14} \text { or } P \text {. falciparum (O) } \\
42 \text {. }\end{array}$ & $\begin{array}{l}\text { In dinoflagellates, Alexandrium } \\
\text { tamarense produces toxins against } \\
\text { the predator Polykrikos kofoidii, } \\
\text { thereby protecting A. fundyense }{ }^{92} \text {. }\end{array}$ \\
\hline $\begin{array}{l}\text { Immune trade-off: } \\
\text { One symbiont (O) stimulates } \\
\text { one branch of the immune } \\
\text { system }(\diamond) \text { and this prevents } \\
\text { the host from mounting } \\
\text { another response }(\diamond) \text { against } \\
\text { another symbiont (0). }\end{array}$ & $\begin{array}{l}\therefore 0 \\
\therefore 0 \\
\therefore 0 \\
\therefore 0\end{array}$ & $\begin{array}{l}\text { Infection success } \\
\text { Development }\end{array}$ & $\begin{array}{l}\text { Tomato spotted wilt and tobacco mosaic } \\
\text { viruses }(0) \text { induce salicylic acid plant } \\
\text { defences }(\diamond) \text {, preventing host plants from } \\
\text { mounting jasmonic acid defences ( }) \\
\text { against the ecto-parasite Frankliniella } \\
\text { occidentalis }(0)^{20,21} \text {. }\end{array}$ & $\begin{array}{l}\text { At low densities the presence of } \\
\text { two prey species (clams Macoma } \\
\text { balthica and juvenile blue crabs } \\
\text { Callinectes sapidus) reduces the } \\
\text { rate of predation by adult blue } \\
\text { crabs on both prey species }^{93} \text {. }\end{array}$ \\
\hline $\begin{array}{l}\text { Mechanical } \\
\text { One symbiont (O) damages } \\
\text { host (O) mechanical barriers, } \\
\text { creating an entry/exit point for } \\
\text { another symbiont (O). }\end{array}$ & & $\begin{array}{l}\text { Infection success } \\
\text { Exit from the host } \\
\text { Transmission }\end{array}$ & $\begin{array}{l}\text { Epidermal injuries and changes in the skin } \\
\text { microbiome induced by the scabies mite } \\
\text { Sarcoptes scabiei }(0) \text { in pigs }(O) \text { are } \\
\text { correlated with increased susceptibility to } \\
\text { Staphylococcus chromogenes }(0)^{23} \text {. }\end{array}$ & $\begin{array}{l}\text { Grazing of wild ungulates on dead } \\
\text { plant matter facilitates cattle as it } \\
\text { increases access to fresh grass } \\
\text { material underneath } \\
\text { 94. }\end{array}$ \\
\hline $\begin{array}{l}\text { Behavioural manipulation } \\
\text { One symbiont (O) induces } \\
\text { behavioural changes in its } \\
\text { host (O), which increases the } \\
\text { transmission of other } \\
\text { symbionts (O) to new hosts }(\bigcirc)\end{array}$ & & $\begin{array}{l}\text { Infection success } \\
\text { Transmission }\end{array}$ & $\begin{array}{l}\text { Cestode (O) and microsporidian (O) } \\
\text { parasites infecting Artemia shrimps }(O) \\
\text { induce host swarming behaviour at the } \\
\text { water surface, which increases both } \\
\text { microsporidian }(0) \text { transmission to new } \\
\text { hosts }(0) \text { swarming underneath, and the } \\
\text { chances of being preyed upon by flamingos, } \\
\text { the definitive host of the cestode }(0)^{26} \text {. }\end{array}$ & $\begin{array}{l}\text { A ciliate predator, Favella } \\
\text { ehrenbergii, facilitates the } \\
\text { dinoflagellate predator, } \\
\text { Gyrodinium dominans, by } \\
\text { immobilising its dinoflagellate } \\
\text { prey, Scrippsiella trochoidea }{ }^{95} \text {. }\end{array}$ \\
\hline $\begin{array}{l}\text { Reproductive manipulation } \\
\text { (vertical hitchhiking) of infected } \\
\text { hosts }(O) \text { by a vertically- } \\
\text { transmitted symbiont (O) } \\
\text { benefits another symbiont }(0) \\
\text { with the same transmission } \\
\text { mode. }\end{array}$ & $\begin{array}{l}+\infty 0 \\
0 \\
0 \\
0\end{array}$ & Transmission & $\begin{array}{l}\text { The vertically-transmitted bacteria } \\
\text { Wolbachia and Cardinium (OO) manipulate } \\
\text { the reproduction of their spider-mite } \\
\text { hosts (O) thereby increasing the } \\
\text { transmission of both }(00)^{28} \text {. }\end{array}$ & $\begin{array}{l}\text { Grazing by cattle triggers the } \\
\text { growth of new shoots improving } \\
\text { the food quality for the red deer } \\
\text { Cervus elaphus }\end{array}$ \\
\hline
\end{tabular}

Fig. 3 Mechanisms underlying symbiont facilitation and parallels with free-living organisms. Blue circles: facilitating symbionts; green circles: facilitated symbionts; yellow shading: within-host environment; blue shading: between-host environment; grey or yellow circles: host; purple circles: resource; diamonds: host immune response; blue arrows: facilitation (solid: direct; dashed: indirect); black arrows: other types of effects (solid: enabled; dotted: cancelled). Traits facilitated are categorised as 'development' (i.e. symbiont's growth or differentiation) in the within-host environment, 'infection success' (i.e. host entry or establishment) and 'exit from the host' at the interface between the within- and between-host environment, and 'transmission' in the between-host environment 
Table 1 Factors affecting the likelihood or strength of facilitation between symbionts and parallel examples for free-living organisms

Examples for symbiont-symbiont interactions

Examples with free-living organisms

Intrinsic factors

Developmental stage

Genetic identity

Facilitated/facilitators

Resource/host

Functional overlap

Genetic diversity

Phylogenetic distance

Environmental

Prevalence of each player

Order of arrival (priority

effects or sequential

infection)

Environmental stress

Site/localisation
Interactions between microparasites in rodents can be facilitative when infections are new, but competitive when chronic (or vice versa) ${ }^{40}$.

Facilitation only occurs between certain genotypes of spider mites on tomato plants ${ }^{97}$.

Facilitation between two strains of powdery mildew only occurs in more susceptible genotypes of ribwort plantain hosts $^{77}$.

In aphids, co-occuring bacterial endosymbionts often display complementary (protective and/or nutritional) functions for their hosts ${ }^{41}$, which increases facilitation via enhanced host fitness.

Infection success of trematode eye-fluke parasites in rainbow trout is higher when the inoculum contains greater symbiont diversity ${ }^{99}$.

Facilitation occurs between both closely (e.g. two rodent malaria parasites ${ }^{18}$ ) and distantly related species (e.g. microparasites such as viruses, bacteria, fungi or protozoa, and macroparasites such as helminths ${ }^{22}$ ).
The facilitative interaction between a nurse plant and a beneficiary becomes competitive as the beneficiary ages $^{91}$.

Only some genotypes of dinoflagellate prey are able to facilitate others by producing toxins that kill a predatory dinoflagellate ${ }^{92}$.

The genotype of a host plant can change the intensity of facilitative interactions occurring between beneficiaries ${ }^{98}$

Character displacement reducing overlap in resource use between interacting free-living decomposer bacteria leads to the emergence of facilitation, as some species evolve to use the waste products of other species ${ }^{48}$. Species diversity of aquatic arthropods increases resource consumption compared to monospecies cultures ${ }^{63}$.

Nurse and beneficiary plants are often phylogenetically distant ${ }^{7}$.
The likelihood of facilitation is affected by the density of the facilitator (e.g. low density of a rodent malaria parasite facilitates another in mice ${ }^{18}$, and a high density of HIV facilitates a human malaria parasite ${ }^{42}$ ).

Facilitation occurs only if the facilitator is the first to infect the host (e.g. rodent malaria parasites in mice ${ }^{18}$, and trematode eye-fluke genotypes in rainbow trout ${ }^{99}$ ).

The strength of facilitation between two strains of powdery mildew can be reduced in more resistant ribwort plantain hosts 77

The site of infection within a host determines whether facilitation occurs (e.g. scabies mites facilitate opportunistic pathogens at the wound site only ${ }^{23}$ ).
The strength of facilitation by the co-occurring facilitators, ribbed mussels and fiddler crabs, is positively correlated with their respective density 98 .

Recruitment of a new grassland plant species establishing in an environment depends on the plant species that are already present ${ }^{100}$.

Facilitation occurs under more stressful conditions ${ }^{34}$, but might disappear at the harshest end of the stress gradient (the stress-gradient hypothesis) ${ }^{34}$.

In sessile organisms, such as plants, the condition of the micro-site (soil, topography, etc) affects the intensity of the interaction among individuals ${ }^{91}$. through a shortened infection duration ${ }^{37}$. Indeed, mathematical models parameterised from laboratory data show that facilitation measured as higher within-host growth does not always result in more severe epidemics ${ }^{18}$. Alternatively, the withinhost effects of one symbiont (e.g. increased host fecundity leading to larger host populations) might facilitate another in the between-host environment (e.g. because there are more available hosts).

As highlighted by Alizon and Michalakis ${ }^{36}$, a fitness-based approach, which encompasses the entire symbiont life cycle, should be adopted when studying facilitation. This provides an estimate of total symbiont fitness rather than individual fitness components, and accounts for potential pleiotropic effects of facilitation on different traits (or hosts for multi-host symbionts ${ }^{26}$ ). Although it can be complicated to measure the number of secondary infections generated from singly vs multiply infected hosts, several system-specific alternatives can be used to estimate symbiont fitness ${ }^{36}$. This integrative approach should aid identifying the occurrence of facilitation (e.g. see Box 2), although it may be unrealistic to apply it to (long-lived) plants. For instance, Schöb et al. ${ }^{39}$ highlight that identifying costs of facilitation based on measures of reproductive output during one season fails to incorporate possible compensation via higher survival in longlived facilitators.

\section{Ecological and evolutionary drivers of symbiont-symbiont facilitation}

Is facilitation 'just' ecological?. The literature on free-living organisms has identified a number of conditions favouring the occurrence of facilitation. We summarise these conditions for symbionts and draw parallels with free-living organisms in Table 1 . The next question is whether these interactions persist for a sufficiently long time period, such that the facilitator may represent a selection pressure to which the facilitated can respond, and vice versa. The maintenance of, or selection for, facilitation between species thus requires that such organisms encounter one another frequently ${ }^{40,41}$. Factors increasing the likelihood that symbionts find themselves in the same host might be shared transmission routes ${ }^{27}$, or high prevalence in host populations ${ }^{42}$. In general, given the vast amount of evidence that has accumulated in recent decades showing that ecology and evolution operate at similar timescales (e.g. see ref. ${ }^{43}$ ), it seems unreasonable to consider that facilitation will not be shaped by evolution. For instance, the stress-gradient hypothesis predicts the ecological conditions that favour facilitation ${ }^{34}$. If these conditions are constant during a given number of generations, this might select for responses in the facilitator to the facilitated, and vice versa. Similarly, it has been shown that facilitation among plants tends to occur among organisms that are more 


\section{Box 2. Experimental evolution of facilitation in multiple infections}

Experimental evolution is a powerful method to study the evolution of facilitation (as for competition), and its consequences for symbiont virulence and transmission. This technique enables symbiont epidemiology (demography and persistence) and evolution (genetic change) to be tracked over multiple host and symbiont generations in single and multiple infections. Furthermore, facilitation occurs between many symbiont species amenable to selection (Supplementary Table 1).

The effects of facilitation on symbiont evolution could be uncovered by allowing (i) the coevolution of both 'facilitator' and 'facilitated' symbionts in multiple infections, versus (ii) their evolution in the presence of a naive 'facilitator' or 'facilitated' (i.e. a symbiont which does not evolve in a multiply infected host), and (iii) their evolution in single infections (Figure 4). The consequences of facilitation should be assessed by measuring virulence- and transmission-related traits of evolved symbionts when tested in single and multiple infections (e.g. see ref. ${ }^{9}$ ). However, it is not always possible to isolate different symbionts from a multiply infected host (e.g. microsymbionts or strains of the same species) ${ }^{8}$. Modelling approaches should thus be implemented here to elucidate, from the infection phenotype, the mechanisms at play in a particular symbiont interaction ${ }^{8}$. Alternatively, the specific role of different co-occurring facilitation mechanisms, such as immune- and resource-mediated, could be disentangled by manipulation of the host physiology, and by using mutant hosts lacking induced immunity to particular symbionts. Such studies might also highlight how different mechanisms, or the symmetry of the interaction $(+/+,+/-$ or $+/ 0)$ impact the evolution of facilitation.

a

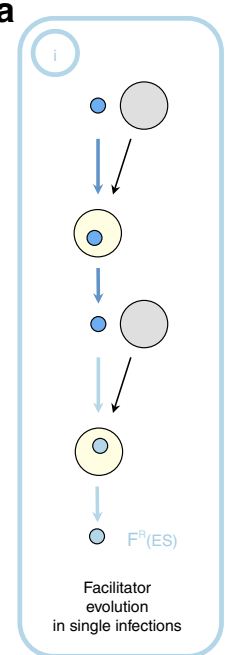

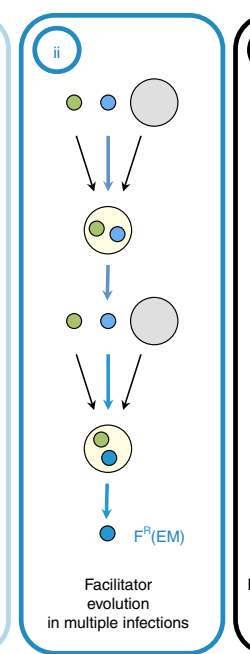
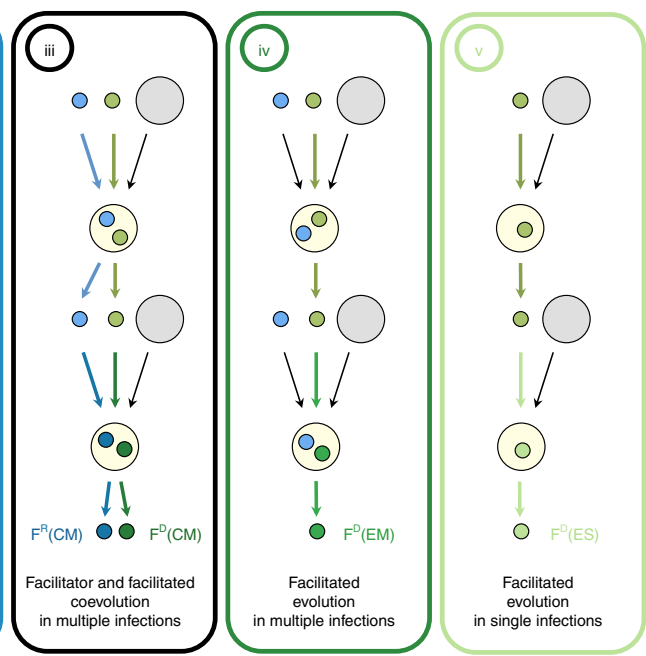

b

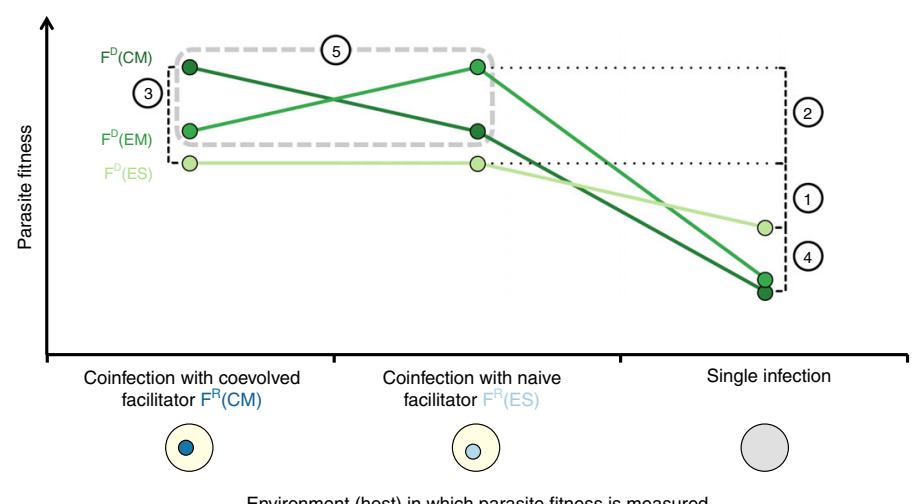

Fig. 4 Proposed experimental design to test the evolution of facilitation. a Experimental design required to measure evolved responses to facilitation. Small green circles: facilitated symbionts $\left(F^{D}\right)$; small blue circles: facilitator symbionts $\left(F^{R}\right)$; big grey circles: hosts. Bold coloured arrows: (co)evolving players; thin black arrows: naive players (i.e. introduced from a naive base population at each generation). Treatments: (i) evolution of the facilitator in single infections: $\mathrm{F}^{\mathrm{R}}(\mathrm{ES})$; (ii) evolution of the facilitator in multiple infections: $\mathrm{F}^{\mathrm{R}}(\mathrm{EM})$; (iii) coevolution of the facilitated and facilitator in multiple infection: $\mathrm{F}^{\mathrm{R}}(\mathrm{CM})$ and $\mathrm{F}^{\mathrm{D}}(\mathrm{CM})$, respectively; (iv) evolution of the facilitated in multiple infections: $\mathrm{F}^{\mathrm{D}}(\mathrm{EM})$; ( $\mathrm{v}$ ) evolution of the facilitated in single infections: $\mathrm{F}^{\mathrm{D}}(\mathrm{ES})$. $\mathbf{b}$ Example of a possible evolved response of local adaptation in which facilitated symbionts have higher fitness when assayed in the infection environment in which they evolved. (1) Facilitation; (2) adaptation to the presence of a facilitator; (3) adaptation to the presence of a coevolved facilitator; (4) cost of adaptation to the facilitator; (5) local adaptation to either a coevolved or evolved facilitator

phylogenetically distant than expected by chance ${ }^{7,44}$. Once this interaction is established, and if sufficiently stable over time, it is likely to exert selection on the individuals involved.

Facilitation may not only be selected following its emergence, but its emergence may be driven by evolution due to kin selection or to resolve conflicts. For instance, a novel cooperative behaviour (fibril production enhancing group migration) evolved in experimental lineages of the soil bacterium Myxococcus xanthus ${ }^{45}$. Moreover, character displacement in response to competition ${ }^{46}$ may decrease functional overlap between two species, which in turn could increase the likelihood of facilitative interactions ${ }^{47}$. For example, in 


\section{Box 3. Intra- versus interspecific facilitation: Is there a difference?}

Typically, the study of facilitation considers interspecific interactions. In contrast, positive interactions between conspecifics are studied under the umbrella of cooperation, where interactions are $+/+$. However, the presence of cheaters who benefit from, but do not partake in 'common good behaviours' are common, generating $+/-$ or $+/ 0$ interactions ${ }^{55}$. A recent review ${ }^{3}$ highlights that within- and between species cooperation are not different evolutionary phenomena. Instead, differences between intra- and interspecific cooperation are continuous along a (phylogenetic) relatedness axis, because cooperating with an unrelated conspecific or heterospecific partner is similar. Furthermore, they discuss similarities between inter- and intraspecific cooperation across additional axes-supplied goods/services, resource competition, strategy sets and evolutionary rates-also relevant to the evolution of symbiont-symbiont facilitation ${ }^{3}$.

Another review 8 addressing virulence evolution in multiple infections, discusses similarities between multi-strain versus multi-species infections. They highlight that, as a two species model ${ }^{70}$ assumes that interacting species are asexual, the inter and intra-specific similarities are equivalent when they interact via the same mechanism ${ }^{8}$. Furthermore, there is no clear theory on how the likelihood of exchanging genetic material matters to virulence ${ }^{8}$. Indeed, whether facilitation benefits conspecifics or heterospecifics depends mostly on the ability of individuals to exploit the modified host environment or gene product. For instance, host immunosuppression and siderophore production should benefit both conspecifics and heterospecifics $9,56,58$. Note, however, that unrelated individuals of the same or different species exploiting the common good being produced might counter-select facilitation $9,49-51$. Indeed, cooperation with kin, which increases the inclusive fitness of the facilitator, occurs only in intra-specific interactions ${ }^{3}$. Nevertheless, parallels might be drawn with interspecific interactions if there are phenotypic correlations between individuals partaking in a mutualism where contributing to a common good, increases the fitness of all actors ${ }^{3}$.

Facilitation can, however, be unique to interspecific interactions when it occurs via a mechanism or product that the facilitated symbiont cannot generate $^{3}$. For example, when facilitation occurs via host immune trade-offs when symbiont stimulation of one branch of the immune system prevents the host from mounting an effective response against a second ${ }^{21,22}$. Similarly, transcapsidation or transcomplementation ${ }^{15,16}$, as well as nested symbionts $^{17}$ (Fig. 3), might only apply to interspecific interactions.

free-living bacteria, facilitation can emerge due to a niche shift in response to competition for a common resource when one species evolves to exploit the waste products of another ${ }^{48}$. Similarly, functional overlap between bacterial endosymbionts in the lachnid aphid may have selected for function partitioning and complementation, such as between Buchnera aphidicola and Serratia symbiotica (the former has lost certain genes whose functions are encoded by the latter $)^{41}$.

Conditions favouring the evolution of facilitation. A main factor determining whether facilitation will evolve is the symmetry of the interaction ${ }^{2,39}$. In general, facilitation is predicted to be selected when the interaction is reciprocal $(+/+$; mutualism/ cooperation), hence when the facilitator also experiences a net benefit from the interaction ${ }^{2}$. This is also predicted by inclusivefitness models where cooperation between symbionts enables kin to exploit the environment and is thus selected in the presence of related individuals $\mathrm{s}^{4-51}$. Similarly, persistent cooperation can occur between non-kin ${ }^{3}$ (see Box 3). For example, two different bacteriophages, in a $+/+$ relationship, evolved the co-packaging of their genomes for transmission to new hosts ${ }^{52}$. Unfortunately, this study was done with a single replicate selection line (i.e. there was no replication, as in experimental evolution replication is measured at the population/line level).

Facilitation might still evolve if it bears no cost to the facilitator $(+/ 0$; commensalism). In this case, the plant literature predicts that evolution should occur unilaterally in the facilitated species only ${ }^{2}$. The symbiont literature, in turn, predicts that, although facilitation is not adaptive per se, it might be indirectly selected if the trait leading to facilitation also benefits, or is genetically correlated with a trait that benefits, the facilitator ${ }^{53}$. For instance, facilitation via immunosuppression can be selected when it has pleiotropic beneficial effects on transmission ${ }^{53}$, but empirical evidence is lacking.

Finally, facilitation might evolve even when it negatively impacts the facilitator $(+/-)$. In the plant literature, these interactions (e.g. nurse plant species negatively impacted by beneficiaries ${ }^{39}$ ) are predicted to exhibit lower evolutionary stability than mutualistic or commensal interactions, selecting for traits that eliminate associated costs; promoting tolerance or resistance to colonisation by the facilitated ${ }^{2}$, thereby switching the interaction towards $+/ 0$ or disappearing, respectively. Among symbionts, facilitation might be maintained if the benefit of host manipulation outweighs the cost imposed by the facilitated symbiont (see 'Evolutionary dynamics of facilitation' section below). Another possibility is that this type of interaction might produce an antagonistic, coevolutionary arms race between the facilitator and facilitated, as demonstrated between Staphylococcus aureus and Enterococcus faecalis over the exploitation of public goods ${ }^{10}$. These possibilities can be extended to plants and other free-living species, as equivalent studies are currently lacking in this area.

Moreover, interactions between symbionts and their host may also affect the probability that facilitation will evolve. Indeed, whether facilitation evolves more or less frequently among host parasites or among host mutualists remains an open question (see Box 4).

Evolutionary dynamics of facilitation. Facilitation between symbionts might not be permanent, such that the symmetry defined above $(+/+,+/ 0$ and $+/-)$ is transitory. Consistent with this, public good models predict that cooperation should be counter-selected in the presence of non-kin ${ }^{49,50}$, or that facilitators should evolve to monopolise the resources they make available, thus shifting the interaction away from asymmetric facilitation ${ }^{54}$. However, in the latter case cheaters might also evolve to evade such monopolisation as shown in free-living systems ${ }^{55}$, again shifting the interaction towards asymmetric facilitation. Therefore, if players engage in arms races, facilitation might be an important force driving the evolutionary dynamics of a multiple infection even if it only occurs sporadically.

Such dynamical interactions, characterised by an arms race, might occur between herbivorous spider mite species, which make plants more suitable for themselves and competitors through down-regulation of plant defences ${ }^{56-58}$, but that also exclude competitors via highly localised down-regulation ${ }^{57}$ or the production of dense $\mathrm{web}^{59}$. Among plants, interactions switching between competition and facilitation due to environmental variation have been widely reported (reviewed in ref. ${ }^{11}$ ). However, coevolutionary dynamics of facilitation between freeliving organisms with asymmetric facilitation remains untested (Box 4). To our knowledge, the only example of experimental 


\section{Box 4. Outstanding questions}

- Factors affecting the occurrence of facilitation between symbionts

Is facilitation more likely to occur between vertically transmitted symbionts or horizontally transmitted symbionts with direct transmission than between symbionts with complex life-cycles or ectosymbionts?

Does the stress-gradient hypotheses apply to facilitation between symbionts? (e.g. How often are host switches associated with facilitation?)

Are host condition or genetic background more important for predicting transmission than facilitation per se?

\section{- Factors affecting the evolution of facilitation between symbionts}

What is the prevalence of multiply infected hosts required for facilitation to be selected?

Is facilitation among host mutualists more likely to evolve than facilitation among parasites?

\section{- (Co)evolutionary dynamics of facilitation between symbionts}

How does (co)evolving with a facilitator impact the ability of the facilitated symbiont to exploit facilitation?

Does (co)evolution between facilitated and facilitator species select for reduced facilitation?

Is coevolution between facilitated and facilitator species characterised by an arms race?

Are evolved responses of the facilitator and facilitated symbionts plastic? If so, how would this impact (co)evolution between players?

- Evolutionary consequences of facilitation between symbionts

Does facilitation in multiple infections select for lower or higher levels of virulence and transmission?

Is it possible to disentangle the impact of facilitation from that of competition on virulence evolution?

\section{- Consequences of facilitation for disease management}

Would efforts focussing on facilitator symbionts be a good strategy to control disease?

How might the evolution of plastic responses in facilitator and facilitated symbionts impact control measures?

evolution of an asymmetric interaction shows facilitation loss after ten host generations ${ }^{9}$. Indeed, S. aureus coevolved with $E$. faecalis produced fewer siderophores (iron scavenging molecules) than the ancestral population and than S. aureus evolving alone ${ }^{9}$. This is probably because siderophores benefit $E$. faecalis, but the latter suppresses $S$. aureus growth ${ }^{9}$. However, corroboration of this conclusion would require experimental coevolution with mutant E. faecalis that do not benefit from siderophores (see Box 2).

\section{Ecological and evolutionary consequences of facilitation}

Persistence and diversification. Facilitation between free-living organisms can increase the range distribution of a facilitated species by allowing its recruitment into environments to which it is not adapted ${ }^{1}$. For instance, dryland vegetation simulation models show that facilitation extends regions in which facilitated species can survive due to resource concentration by facilitator species $^{60}$. Similarly, banded mussel patterns are predicted to permit species persistence in otherwise food scarce conditions ${ }^{61}$. Niche extension due to facilitation may also increase species and phylogenetic diversity ${ }^{5,7}$. Moreover, selection for increased facilitation is predicted to reduce extinction risk in spatially subdivided populations with local, but not global, dispersal ${ }^{6}$. Whether such predictions also apply to facilitation between symbionts is a timely issue and has, to our knowledge, not been addressed. Indeed, both host range expansion and parasite diversity have important consequences for disease management.

Host health and virulence evolution. Knowledge stemming from studies of facilitation between free-living organisms could help predict the effects of facilitation between symbionts on host health. For instance, in harsh environments, facilitation can lead to the aggregation of individuals in space ${ }^{62}$, which, in turn, may increase ecosystem productivity compared to homogeneous distributions (e.g. mussel beds $s^{61}$ and dryland vegetation ${ }^{60}$ ). Moreover, empirical studies have shown that inter-specific facilitation can increase ecosystem functioning more generally ${ }^{34,63}$. This may also apply to facilitation between host mutualistic symbionts, which positively impact host health ${ }^{13,47}$.
These predictions from the literature on free-living organisms are, however, ignoring cases where facilitated species have negative effects on their environment. For instance, facilitation of invasive plant species (e.g. by other invasive plant species ${ }^{64}$, or herbivores ${ }^{65}$ ) may have deleterious consequences for ecosystem functioning reducing the biomass of resident species. Similarly, when facilitated symbionts are host parasites, laboratory observations show that facilitation often has negative impacts on host health (Supplementary Table 1). For example, a recent survey shows that multiple infections in humans can lead to higher parasite abundances and poorer host condition compared to single infections ${ }^{66}$. Likewise, mice infected with Bordatella bronchiseptica and Heligmosoides polygyris (see Supplementary Table 1) suffer higher mortality (accompanied by increased bacteria growth and helminth transmission) than those infected with a single species ${ }^{67}$. Another study shows that honey bee colony collapse might be attributed to immunosuppression caused by the mite Varroa destructor, promoting deformed wing virus growth, which is benign in single infections ${ }^{68}$.

Facilitation may also affect host health indirectly, via its effect upon virulence evolution. Facilitation is predicted to select for increased virulence by some theoretical models. Indeed, immunosuppression by one parasite might facilitate infection by a second, but subsequent competition for host resources can select for higher virulence ${ }^{30}$. Similarly, evolution of higher virulence is predicted in a superinfection scenario, where a first parasite facilitates infection and replacement by a second ${ }^{69}$ (this reduces infection duration, which selects for higher virulence). Finally, in inclusive fitness models, the production of public goods leads to elevated symbiont growth, which generally correlates positively with virulence ${ }^{49}$ (but see ref. ${ }^{51}$ ).

Unfortunately, levels of virulence measured in empirical studies are not always the same as those predicted in theoretical models. Indeed, empirical studies usually measure virulence in individual hosts, within a single host generation (see examples in Table S1), whereas mathematical models analyse virulence evolution over several host generations at the population level ${ }^{8}$. Choisy and de Roode ${ }^{70}$ formalise this in a theoretical model predicting higher virulence in multiple infections that cause immunosuppression when symbionts have not evolved together, 
thus in the short-term. However, they also show that, in the longterm, evolution of this system selects for lower virulence, because of a longer infection duration in immunosuppressed hosts ${ }^{70}$. Lower virulence is also predicted to evolve when there is cotransmission of two symbionts (Box 1), one of them being a 'helper' required for transmission of the other ${ }^{71}$. This is because co-transmission, aligning the interests of co-infecting strains, decreases selection for increased within-host competition ${ }^{71}$.

The latter model illustrates the complex interplay between competition and facilitation that probably underlies most interactions between symbionts. As described earlier, an interaction is considered to be facilitation if its net effect is greater than that of competition. Virulence evolution will thus hinge upon the relative strength of these interactions, and the traits upon which they act. As for facilitation, competition between parasites in a multiple infection can select for higher or lower virulence ${ }^{8}$, or for the coexistence of strains with different levels of virulence ${ }^{72}$. A comprehensive understanding of virulence evolution due to facilitation thus also requires knowledge about the interplay between facilitation and competition, and underlying mechanisms. This could be investigated, for instance, in a system where the parasite life-stages engaging in each interaction are clearly defined (e.g. facilitation during the infection process followed by within-host competition for shared host resources ${ }^{30}$; see Boxes 2 and 4).

Furthermore, although host health is generally the read-out of virulence, it can be difficult to evaluate the relative contribution of each symbiont in multiple infections. This is easily measured when virulence and growth are correlated and when symbionts can be distinguished in a multiple infection ${ }^{8}$. However, virulence is not always related to symbiont growth, as assumed by most theoretical models, but might be due to immunopathology $y^{73,74}$. In such cases, symbionts in a multiple infection with facilitation might interact in such a way that virulence does not correspond to the sum of the virulence measured in each single infection. Similarly, the combined impact of host mutualists might be synergetic, additive or non-additive ${ }^{47}$.

Unfortunately, empirical tests of virulence evolution (i.e. across generations) in facilitating multiple infections are as yet extremely scarce $(\text { Box } 2)^{8}$. Indeed, one study in which co-transmission evolved did not measure the virulence of the evolved viruses ${ }^{52}$. Others, consistent with inclusive fitness models ${ }^{49-51}$, found reduced virulence when bacteria producing public goods (e.g. Bt cry toxins produced by the Btk rif ${ }^{\mathrm{R}}$ strain of Bacillus thuringiensis $^{75}$, or siderophores produced by $S$. aureus ${ }^{9}$ ) evolved in the presence of competitors that can also exploit them (e.g. $B$. thuringiensis Btt $\operatorname{spec}^{\mathrm{R}}$ strain, or E. faecalis, respectively). These two systems could be exploited to disentangle the relative importance of competition versus facilitation on the evolution of virulence.

\section{Effects on symbiont dynamics and disease management}

Transmission and epidemiology. Facilitating symbionts can enhance the transmission of (other) pathogens. For example, for super-shedding events of HIV in humans ${ }^{24}$, and of helminth worms in mice 67 , multiply infected individual hosts shed disproportionate numbers of transmissible stages. Moreover, transient effects of facilitation might enable a symbiont to exceed an 'outbreak threshold'76, and cause epidemics even after facilitation has abated. However, true understanding of the long-term consequences of facilitation for symbiont epidemiology remains elusive.

Effects of facilitation on epidemiology have been demonstrated via long-term tracking of multiple infections in field populations. Indeed, one 5-year study, showed that the probability of infection was often higher for voles already harbouring another symbiont compared to uninfected individuals ${ }^{40}$. Alternatively, field observations can be corroborated with common garden experiments measuring symbiont transmission. For example, the transmission of the fungus Podosphaera plantaginis was higher from multiply versus singly infected Plantago lanceolata plants, which might explain the more severe epidemics observed in populations harbouring multiple strains ${ }^{77}$. Moreover, epidemiological models parameterised with empirical data show that predicted patterns coincide with field observations: positive interactions between symbionts can enhance their spread ${ }^{42,78}$. This approach has highlighted that reciprocal positive interactions between HIV and malaria in multiply infected hosts promote the spread of both parasites ${ }^{42}$, and that influenza can cause a higher incidence of pneumonia in human populations ${ }^{78}$. Unfortunately, theoretical models generating hypotheses on the longterm epidemiological consequences of facilitation are still scarce (but see ref. ${ }^{79}$ ).

Disease management. As facilitation between symbionts can promote host range expansion, parasite diversity and epidemics, exacerbate the negative effects of infection on host health and impact virulence evolution, identifying whether certain symbionts are broad-acting facilitators might, in the future, aid the development of effective control strategies. Indeed, biocontrol microorganisms ${ }^{80}$ might be improved if their facilitators are also introduced into risk areas. Moreover, promoting facilitation between mutualist symbionts, such as those of the gut microbiota, that increase general host health ${ }^{13}$ or prevent infection with parasitic symbionts ${ }^{80}$, could also be considered. However, such strategies should be approached with caution, as they may also entail undesirable effects. For example, facilitation of gut microbiota can lead to increased pathogenicity in normally commensal bacteria $^{81}$. Therefore, understanding facilitation might also unveil unforeseen consequences of pest management.

One could also think about alternative strategies, aside from conventional methods of pest or parasite control, to prevent the occurrence of facilitation or facilitators, thereby controlling facilitated parasites. This might be achieved by changing the biotic or abiotic environment such that facilitation is prevented. For instance, the release of cheaters into parasite populations to counter-select strains engaged in social, facilitating behaviours linked with virulence has been suggested ${ }^{82,83}$. However, these strategies might be ineffective due to spatial segregation of facilitator and facilitated strains, or to phenotypic plasticity ${ }^{82,83}$. For instance, if phenotypic plasticity is at play, behaviours associated with facilitation and virulence (e.g. public good production) might be arrested, rather than counter-selected, in the presence of an introduced cheat ${ }^{83}$ (Box 4).

\section{Summary and outlook}

Facilitation improves understanding of host-pathogen interactions. Recent reviews highlight the importance of extending the one host-one symbiont paradigm by studying symbiont interactions in a community ecology context (e.g. see refs. ${ }^{84-86}$ ). However, facilitative interactions among symbionts have only recently gained attention (e.g. see refs. ${ }^{27,81}$ ), which is at odds with the broad knowledge from the plant literature. Indeed, it is clear that many open questions remain (Box 4). For instance, what conditions favour the evolution and maintenance of facilitation among symbionts (host mutualists or parasites, and/or the frequency of multiply infected hosts). And what are the longerterm consequences of facilitation? Does coevolution between facilitating and facilitated symbionts lead to reduced facilitation, 
or to a coevolutionary arms race? Finally, how does symbiont-symbiont facilitation affect epidemiology (transmission), and virulence evolution?

Hence, facilitation may shed light on the study of host-parasite interactions. In this sense, the extensive knowledge acquired from more than thirty years on ecological facilitation among plants may constitute a solid theoretical base to investigate the complexity of symbiont interactions and their consequences for hosts.

Symbiont facilitation informs community ecology and evolution. Understanding facilitative interactions between symbionts might also inform on general principles in community ecology. For example, facilitation is predicted to improve ecosystem functioning ${ }^{63}$, to increase productivity at the community scale, and to expand the realised niche of maladapted species ${ }^{1,5}$. Such predictions have been corroborated by empirical studies ${ }^{44}$, but they would gain from being tested in manipulative experiments. As hosts are a contained environment that can harbour multiple symbiont species and can be tightly controlled and manipulated, they provide an excellent arena to establish causality, and critically test the abovementioned ideas with replication at the community level.

Symbionts can also shed new light on understanding how evolution shapes facilitation. For instance, research on facilitation among free-living organisms has ignored the possibility of an arms race between facilitators and facilitated ${ }^{2,39}$. Placing symbionts at the core of the facilitation literature allows not only considering, but also testing this possibility. Furthermore, given the similar timescales at which ecology and evolution operate, facilitation may be shaped by eco-evolutionary feedbacks. These may not be uncovered in other systems due to long generation times, such as long-lived plant species ${ }^{39}$. The typical short generation time of symbionts and their consequent amenability to experimental (co)evolution (Box 2) make them excellent candidates to address the (eco-)evolutionary consequences of facilitation at several scales.

Therefore, in the study of facilitation, as in many other areas, it is crucial to build bridges between contrasting fields of research, to generate fruitful positive feedbacks at different levels and to open new research avenues.

Received: 26 January 2018 Accepted: 31 August 2018

Published online: 19 November 2018

\section{References}

1. Bruno, J. F., Stachowicz, J. J. \& Bertness, M. D. Inclusion of facilitation into ecological theory. Trends Ecol. Evol. 18, 119-125 (2003). A key review article stating that the role of facilitation driving ecological interactions had been greatly underappreciated in the ecological literature.

2. Bronstein, J. L. The evolution of facilitation and mutualism. J. Ecol. 97, 1160-1170 (2009). Review article postulating the importance of evolution for facilitation among plants.

3. Barker, J. L. et al. Synthesizing perspectives on the evolution of cooperation within and between species. Evolution 71, 814-825 (2017). Review article highlighting the similarities between intra and inter-specific cooperation along five different axes.

4. Hellard, E., Fouchet, D., Vavre, F. \& Pontier, D. Parasite-parasite interactions in the wild: how to detect them? Trends Parasitol. 31, 640-652 (2015).

5. Stachowicz, J. J. Mutualism, facilitation, and the structure of ecological communities. Bioscience 51, 235-246 (2001).

6. Kéfi, S., van Baalen, M., Rietkerk, M. \& Loreau, M. Evolution of local facilitation in arid ecosystems. Am. Nat. 172, E1-E17 (2008).

7. Valiente-Banuet, A. \& Verdú, M. Facilitation can increase the phylogenetic diversity of plant communities. Ecol. Lett. 10, 1029-1036 (2007).

8. Alizon, S., de Roode, J. C. \& Michalakis, Y. Multiple infections and the evolution of virulence. Ecol. Lett. 16, 556-567 (2013). Review article synthesising the theoretical and experimental consequences of competition between symbionts in multiple infections.

9. Ford, S. A., Kao, D., Williams, D. \& King, K. C. Evolution of reduced pathogen virulence. Nat. Commun. 7, 1-9 (2016). Experimental study showing that coevolution between different bacterial species can select for reduced virulence.

10. Ford, S. A., Williams, D., Paterson, S. \& King, K. C. Co-evolutionary dynamics between a defensive microbe and a pathogen driven by fluctuating selection. Mol. Ecol. 26, 1778-1789 (2017).

11. Callaway, R. Positive Interactions and Interdependence in Plant Communities (Springer, 2007). A book reviewing the evidence for the role of inter-specific facilitation in plant communities, the mechanisms involved and the functional consequences.

12. Woyke, T. et al. Symbiosis insights through metagenomic analysis of a microbial consortium. Nature 443, 950-955 (2006).

13. Rakoff-Nahoum, S. et al. The evolution of cooperation within the gut microbiota. Nature 533, 255-259 (2016)

14. Van de Perre, P. et al. Herpes simplex virus and HIV-1: deciphering viral synergy. Lancet Infect. Dis. 8, 490-497 (2008).

15. Syller, J. Facilitative and antagonistic interactions between plant viruses in mixed infections. Mol. Plant Pathol. 13, 204-216 (2012).

16. Froissart, R., Michalakis, Y. \& Blanc, S. Helper componenttranscomplementation in the vector transmission of plant viruses. Phytopathology 92, 576-579 (2002).

17. Herniou, E. A. et al. When parasitic wasps hijacked viruses: genomic and functional evolution of polydnaviruses. Philos. Trans. R. Soc. B 368, 20130051 (2013).

18. Ramiro, R. S., Pollitt, L. C., Mideo, N. \& Reece, S. E. Facilitation through altered resource availability in a mixed-species rodent malaria infection. Ecol. Lett. 19, 1041-1050 (2016). Experimental and theoretical study showing that facilitation between different species of malaria increases virulence in multiply infected hosts, and that facilitation can increase the prevalence of the facilitated species.

19. Zélé, F., Nicot, a, Duron, O. \& Rivero, A. Infection with Wolbachia protects mosquitoes against Plasmodium-induced mortality in a natural system. J. Evol. Biol. 25, 1243-1252 (2012).

20. Abe, $\mathrm{H}$. et al. Antagonistic plant defense system regulated by phytohormones assists interactions among vector insect, thrips and a tospovirus. Plant Cell Physiol. 53, 204-212 (2012).

21. Belliure, B., Janssen, A., Maris, P. C., Peters, D. \& Sabelis, M. W. Herbivore arthropods benefit from vectoring plant viruses. Ecol. Lett. 8, 70-79 (2005).

22. Graham, A. L. Ecological rules governing helminth-microparasite coinfection Proc. Natl Acad. Sci. USA 105, 566-570 (2008). Metaanalysis showing how ressource- and immune-mediated mechanisms mediate facilitative, neutral or competitive interactions across a broad spectrum of parasite taxa in laboratory mice.

23. Swe, P. M., Zakrzewski, M., Kelly, A., Krause, L. \& Fischer, K. Scabies mites alter the skin microbiome and promote growth of opportunistic pathogens in a porcine model. PLoS Negl. Trop. Dis. 8, 11-14 (2014).

24. Cohen, M. S. et al. Reduction of concentration of HIV-1 in semen after treatment of urethritis: implications for prevention of sexual transmission of HIV-1. Lancet 349, 1868-1873 (1997).

25. Cézilly, F., Perrot-Minnot, M. \& Rigaud, T. Cooperation and conflict in host manipulation: interactions among macro-parasites and micro-organisms. Front. Microbiol. 5, 1-10 (2014).

26. Rode, N. et al. Why join groups? Lessons from parasite-manipulated Artemia. Ecol. Lett. 16, 493-501 (2013).

27. Vautrin, E. \& Vavre, F. Interactions between vertically transmitted symbionts: cooperation or conflict? Trends Microbiol. 17, 95-99 (2009).

28. Zhao, D., Chen, D., Ge, C., Gotoh, T. \& Hong, X. Multiple infections with Cardinium and two strains of Wolbachia in the spider mite Tetranychus phaselus Ehara: revealing new forces driving the spread of Wolbachia. PLoS. One. 8, e54964 (2013).

29. Biancotto, A. et al. Upregulation of human cytomegalovirus by HIV type 1 in human lymphoid tissue ex vivo. AIDS Res. Hum. Retrovir. 24, 453-462 (2008).

30. Kamiya, T., Mideo, N. \& Alizon, S. Co-evolution of virulence and immunosuppression through multiple infections. J. Evol. Biol. 31, 995-1005 (2018). peer reviewed by Peer Community In Evolutionary Biology, 149211 Theoretical study showing that simultaneous facilitation (aiding infection) and competition (for shared host resources) between parasites can select for elevated virulence.

31. Cattadori, I. et al. Infections do not predict shedding in co-infections with two helminths from a natural system. Ecology 95, 1684-1692 (2014).

32. Callaway, R., Nadkarni, N. \& Mahall, B. Facilitation and interference of Quercus douglasii on understory productivity in Central California. Ecology 72, 1484-1499 (1991). 
33. Maestre, F. T., Bautista, S. \& Cortina, J. Positive, negative, and net effect in grass-shrubs interactions in Mediterranean semiarid grasslands. Ecology $\mathbf{8 4}$ 3186-3187 (2003).

34. Michalet, R. et al. Do biotic interactions shape both sides of the humped-back model of species richness in plant communities? Ecol. Lett. 9, 767-773 (2006).

35. He, Q., Bertness, M. D. \& Altieri, A. H. Global shifts towards positive species interactions with increasing environmental stress. Ecol. Lett. 16, 695-706 (2013).

36. Alizon, S. \& Michalakis, Y. Adaptive virulence evolution: the good old fitnessbased approach. Trends Ecol. Evol. 30, 248-254 (2015).

37. Anderson, R. M. \& May, R. M. Coevolution of hosts and parasites. Parasitology 85, 411-426 (1982).

38. Zélé, F. et al. Wolbachia increases susceptibility to Plasmodium infection in a natural system. Proc. R. Soc. B 281, 20132837 (2014)

39. Schöb, C. et al. A global analysis of bidirectional interactions in alpine plant communities shows facilitators experiencing strong reciprocal fitness costs. New Phytol. 202, 95-105 (2014).

40. Telfer, S. et al. Species interactions in a parasite community drive infection risk in a wildlife population. Science 330, 243-246 (2010).

41. Douglas, A. E. How multi-partner endosymbioses function. Nat. Rev. Microbiol. 14, 731-743 (2016).

42. Abu-Raddad, L., Patnaik, P. \& Kublin, J. Dual infection with HIV and malaria fuels the spread of both diseases in Sub-Saharan Africa. Science 314, 1603-1606 (2006).

43. Fussmann, G. F., Loreau, M. \& Abrams, P. A. Eco-evolutionary dynamics of communities and ecosystems. Funct. Ecol. 21, 465-477 (2007).

44. Valiente-Banuet, A., Vital Rumebe, A., Verdu, M. \& Callaway, R. M. Modern Quaternary plant lineages promote diversity through facilitation of ancient Tertiary lineages. Proc. Natl. Acad. Sci. USA. 103, 16821-16817 (2006).

45. Velicer, G. J. \& Yu, Y. T. N. Evolution of novel cooperative swarming in the bacterium Myxococcus xanthus. Nature 425, 75-78 (2003). Experimental study showing the evolution of facilitation (cooperative behaviour) between free-living bacteria.

46. MacArthur, R. H. \& Levins, R. The limiting similarity, convergence, and divergence of coexisting species. Am. Nat. 101, 377-385 (1967).

47. Afkhami, M. E., Rudgers, J. A. \& Stachowicz, J. J. Multiple mutualist effects: conflict and synergy in multispecies mutualisms. Ecology 95, 833-844 (2014).

48. Lawrence, D. et al. Species interactions alter evolutionary responses to a novel environment. PLoS Biol. 10, e1001330 (2012).

49. West, S. A. \& Buckling, A. Cooperation, virulence and siderophore production in bacterial parasites. Proc. R. Soc. B 270, 37-44 (2003).

50. Brown, S. P. \& Johnstone, R. A. Cooperation in the dark: signalling and collective action in quorum-sensing bacteria. Proc. R. Soc. B 268, 961-965 (2001).

51. Alizon, S. \& Lion, S. Within-host parasite cooperation and the evolution of virulence. Proc. R. Soc. B 278, 3738-3747 (2011).

52. Sachs, J. L. \& Bull, J. J. Experimental evolution of conflict mediation between genomes. Proc. Natl Acad. Sci. USA 102, 390-395 (2005).

53. Bonhoeffer, S. \& Nowak, M. A. Intra-host versus inter-host selection: Viral strategies of immune function impairment. Proc. Natl Acad. Sci. USA 91, 8062-8066 (1994).

54. Krakauer, D. C., Page, K. M. \& Erwin, D. H. Diversity, dilemmas, and monopolies of niche construction. Am. Nat. 173, 26-40 (2009).

55. Kummerli, R. et al. Co-evolutionary dynamics between public good producers and cheats in the bacterium Pseudomonas aeruginosa. J. Evol. Biol. 28, 2264-2274 (2015).

56. Godinho, D. P., Janssen, A., Dias, T., Cruz, C. \& Magalhães, S. Downregulation of plant defence in a resident spider mite species and its effect upon con- and heterospecifics. Oecologia 180, 161-167 (2016).

57. Glas, J. J. et al. Defense suppression benefits herbivores that have a monopoly on their feeding site but can backfire within natural communities. BMC Biol. 12, 12-98 (2014)

58. Sarmento, R. A. et al. (2011) A herbivore that manipulates plant defence. Ecol. Lett. 14, 229-236 (2011).

59. Sarmento, R. et al. A herbivorous mite down-regulates plant defence and produces web to exclude competitors. PLoS. ONE. 6, e23757 (2011).

60. Kéfi, S., Rietkerk, M., van Baalen, M. \& Loreau, M. Local facilitation, bistability and transitions in arid ecosystems. Theor. Popul. Biol. 71, 367-379 (2007).

61. van de Koppel, J., Rietkerk, M., Dankers, N. \& Herman, P. M. J. Scaledependent feedback and regular spatial patterns in young mussel beds. Am. Nat. 165, E66-E77 (2005).

62. van de Koppel, J. et al. Experimental evidence for spatial self-organization and its emergent effects in mussel bed ecosystems. Science 322, 739-742 (2008).

63. Cardinale, B. J., Palmer, M. A. \& Collins, S. L. Species diversity enhances ecosystem functioning through interspecific facilitation. Nature 415, 426-429 (2002).
64. Flory, S. L. \& Bauer, J. T. Experimental evidence for indirect facilitation among invasive plants. J. Ecol. 102, 12-18 (2014).

65. Blossey, B. \& Gorchov, D. L. Ungulates and invasive species: quantifying impacts and understanding interactions. AoB Plants 9, 1-6 (2017).

66. Griffiths, E. C., Pedersen, A. B., Fenton, A. \& Petchey, O. L. The nature and consequences of coinfection in humans. J. Infect. 63, 200-206 (2011).

67. Lass, S. et al. Generating super-shedders: co-infection increases bacterial load and egg production of a gastrointestinal helminth. J. R. Soc. Interface 10, 20120588 (2012).

68. Nazzi, F. et al. Synergistic parasite-pathogen interactions mediated by host immunity can drive the collapse of honeybee colonies. PLoS Biol. 8, e1002735 (2012).

69. Kada, S. \& Lion, S. Superinfection and the coevolution of parasite virulence and host recovery. J. Evol. Biol. 28, 2285-2299 (2015).

70. Choisy, M. \& de Roode, J. C. Mixed infections and the evolution of virulence: effects of resource competition, parasite plasticity, and impaired host immunity. Am. Nat. 175, E105-E118 (2010). Theoretical study showing that facilitation between parasites via host immunosuppression can select for reduced virulence due to a longer infection duration.

71. Alizon, S. Parasite co-transmission and the evolutionary epidemiology of virulence. Evolution 67, 921-933 (2013).

72. Alizon, S. \& van Baalen, M. Multiple infections, immune dynamics, and the evolution of virulence. Am. Nat. 172, E150-E168 (2008).

73. Graham, A. L., Allen, J. E. \& Read, A. F. Evolutionary causes and consequences of immunopathology. Annu. Rev. Ecol. Evol. Syst. 36, 373-397 (2005).

74. Weigert, M. et al. Manipulating virulence factor availability can have complex consequences for infections. Evol. Appl. 10, 91-101 (2017).

75. Garbutt, J., Bonsall, M. B., Wright, D. J. \& Raymond, B. Antagonistic competition moderates virulence in Bacillus thuringiensis. Ecol. Lett. 14, 765-772 (2011).

76. Hartfield, M. \& Alizon, S. Introducing the outbreak threshold in epidemiology. PLoS Biol. 9, 9-12 (2013).

77. Susi, H., Barrès, B., Vale, P. F. \& Laine, A.-L. Co-infection alters population dynamics of infectious disease. Nat. Commun. 6, 5975 (2015).

78. Shrestha, S., Foxman, B., Berus, J. \& Panhuis, W. G. Van The role of influenza in the epidemiology of pneumonia. Sci. Rep. 5, 15314 (2015).

79. Sofonea, M. T., Alizon, S. \& Michalakis, Y. Exposing the diversity of multiple infection patterns. J. Theor. Biol. 419, 278-289 (2017).

80. McNally, L. \& Brown, S. P. Building the microbiome in health and disease: niche construction and social conflict in bacteria. Philos. Trans. R. Soc. B 370, 20140298 (2015).

81. Almand, E. A., Moore, M. D. \& Jaykus, L. A. Virus-bacteria interactions: an emerging topic in human infection. Viruses 9, 1-10 (2017).

82. Brown, S., West, S. A., Stephen, P. \& Griffin, A. S. Social evolution in microorganisms and a Trojan horse approach to medical intervention strategies. Proc. R. Soc. B 364, 3157-3168 (2009).

83. Leggett, H. C., Brown, S. P. \& Reece, S. E. War and peace: social interactions in infections. Philos. Trans. R. Soc. B 369, 20130365 (2014).

84. Johnson, P. T. J., de Roode, J. C. \& Fenton, A. Why infectious disease research needs community ecology. Science 349, 1259504-1-1259504-9 (2015).

85. Pedersen, A. B. \& Fenton, A. Emphasizing the ecology in parasite community ecology. Trends Ecol. Evol. 22, 133-139 (2007).

86. Seabloom, E. W. et al. The community ecology of pathogens: coinfection, coexistence and community composition. Ecol. Lett. 18, 401-415 (2015).

87. Heil, M. \& Karban, R. Explaining evolution of plant communication by airborne signals. Trends Ecol. Evol. 25, 137-144 (2010).

88. Márquez, R., Corredor, G., Galvis, C., Góes, D. \& Amézquita, A. Range extension of the critically endangered true poison-dart frog, Phyllobates terribilis (Anura: Dendrobatidae), in western Colombia Acta Herpetol. 7, 341-345 (2012)

89. Greenwood, P. G. Acquisition and use of nematocysts by cnidarian predators. Toxicon 54, 1065-1070 (2009)

90. Bhattacharya, D., Pelletreau, K. N., Price, D. C., Sarver, K. E. \& Rumpho, M. E. Genome analysis of Elysia chlorotica egg DNA provides no evidence for horizontal gene transfer into the germ line of this kleptoplastic mollusc. Mol. Biol. 30, 1843-1852 (2013).

91. Soliveres, S., Smit, C. \& Maestre, F. T. Moving forward on facilitation research: response to changing environments and effects on the diversity, functioning and evolution of plant communities. Biol. Rev. Camb. Philos. Soc. 90, 297-313 (2015).

92. John, U. et al. Intraspecific facilitation by allelochemical mediated grazing protection within a toxigenic dinoflagellate population. Proc. R. Soc. B 282, 20141268 (2015). 
93. Long, W. C., Gamelin, E. F., Johnson, E. G. \& Hines, A. H. Density-dependent indirect effects: apparent mutualism and apparent competition coexist in a two-prey system. Mar. Ecol. Prog. Ser. 456, 139-148 (2012).

94. Odadi, W. O., Karachi, M. K., Abdulrazak, S. A. \& Young, T. P. African wild ungulates compete with or facilitate cattle depending on season. Science 333, 2-4 (2011).

95. Loder, M., Boersma, M., Kraberg, A., Aberle, N. \& Wiltshire, K. Microbial predators promote their competitors: commensalism within an intraguild predation system in microzooplankton. Ecosphere 5, 128 (2014).

96. Gordon, I. Facilitation of red deer grazing by cattle and its impact on red deer performance. J. Appl. Ecol. 25, 1-9 (1998).

97. Orsucci, M., Navajas, M. \& Fellous, S. Genotype-specific interactions between parasitic arthropods. Heredity 118, 260-265 (2016).

98. Hughes, A. R., Moore, A. F. P. \& Piehler, M. F. Independent and interactive effects of two facilitators on their habitat-providing host plant. Spartina Alter. Oikos 123, 488-499 (2014).

99. Klemme, I., Louhi, K. R. \& Karvonen, A. Host infection history modifies coinfection success of multiple parasite genotypes. J. Anim. Ecol. 85, 591-597 (2016).

100. Fukami, T., Bezemer, T., Mortimer, S. \& van der Putten, W. Species divergence and trait convergence in experimental plant community assembly. Ecol. Lett. 8, 1283-1290 (2005).

\section{Acknowledgements}

We would like to dedicate this paper to the memory of Isabelle Olivieri, for being such a great example of a person and a scientist and for having influenced us in so many ways that enumerating them would not fit within the word limit of this Article. We would like to thank Adrián Escudero, Alain Danet, Alex Hall, Franck Prugnolle, Rolf Kümmerli, Virginie Rougeron and Yannis Michalakis for very helpful comments, which have greatly improved the manuscript. This work was funded by an ERC consolidating grant (COMPCON GA 725419) to S.M. and by a PHC-PESSOA grant (38014YC) to S.M. and A.B.D. F.Z. was funded through FCT Post-Doc fellowship (SFRH/BPD/125020/2016). This is ISEM contribution number 2018-165.

\section{Author contributions}

All authors participated in writing the entire manuscript. S.K. mostly contributed sections about facilitation in free-living organisms, and F.Z., S.M. and A.B.D. mostly sections about facilitation between symbionts. F.Z. designed the figures. A.B.D. conceived of the original idea for this review.

\section{Additional information}

Supplementary Information accompanies this paper at https://doi.org/10.1038/s41467018-06779-w.

Competing interests: The authors declare no competing interests.

Reprints and permission information is available online at http://npg.nature.com/ reprintsandpermissions/

Publisher's note: Springer Nature remains neutral with regard to jurisdictional claims in published maps and institutional affiliations.

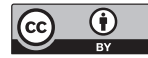

Open Access This article is licensed under a Creative Commons Attribution 4.0 International License, which permits use, sharing, adaptation, distribution and reproduction in any medium or format, as long as you give appropriate credit to the original author(s) and the source, provide a link to the Creative Commons license, and indicate if changes were made. The images or other third party material in this article are included in the article's Creative Commons license, unless indicated otherwise in a credit line to the material. If material is not included in the article's Creative Commons license and your intended use is not permitted by statutory regulation or exceeds the permitted use, you will need to obtain permission directly from the copyright holder. To view a copy of this license, visit http://creativecommons.org/ licenses/by/4.0/.

(C) The Author(s) 2018 